\title{
A Surgical Resident's Perspective about COVID-19 Pandemic: Unique Experience and Lessons Learnt
}

Madhuri Chaudary, ${ }^{1}$ Prakash Kumar Sasmal. ${ }^{2}$

\begin{abstract}
The Experience
History has been repeating itself in the form of pandemics like cholera, swine flu, and smallpox, to name a few, which affect humanity by killing a substantial number of people with each occurrence. After nearly a decade of the swine flu pandemic which caused massive loss of human lives all over the world, the presently ongoing COVID-19 pandemic caused by the severe acute respiratory syndrome coronavirus 2 (SARS-CoV-2) has wholly paralyzed the globe with a rising death toll. COVID-19 or SARS-CoV-2 illness was declared to be a public health emergency of international significance on $30^{\text {th }}$ January 2020 . The outbreak, as first reported in December 2019 in Wuhan province of China, has now spread in almost the entire world, affecting most of the countries worldwide.' In India, though cases started to appear towards the end of January 2020, now cases are skyrocketing despite stringent measures to contain the disease. ${ }^{2}$ Every pandemic teaches people new ways of lifestyle, like the Black Death, which in the year 1346 left us ending the system of serfdom in Europe and introduced the concept of quarantine. $^{3}$
\end{abstract}

As a surgical postgraduate trainee, I had never thought in my life to be experiencing such a situation, especially in the early part of my career. In this short article, I will be sharing my experience during this challenging time, regarding the management of the health crisis in a tertiary care center of a lower-middle-income country.

\section{What I Experienced}

Patient Care: Ever since the outbreak of the COVID-19 in India, the government has implemented a standard operating procedure (SOP) to manage the diagnosed or suspected cases in the hospital. There is frequent training of the residents, irrespective of the specialty, regarding donning and doffing of personal protective equipment (PPE) and handling the ventilators to manage the critically ill patients. The infectiousness and fatality of the SARS-CoV-2 virus have not only spread apprehension amongst the public but created chaos amongst the health care providers.

As a surgical trainee, I am used to handling high-risk surgical patients taking universal precautions, but managing a highly infectious medical condition is the need of the hour. As a surgical resident, I never thought of managing cases with a medical illness, including collecting swabs for RT-PCR and running the screening outpatient departments.

During this critical time, it has become even more difficult to manage a patient with a genuine surgical emergency. Due to the apprehension in my mind about unknowingly encountering a COVID-19 patient and getting exposed, a surgical disease is often clinically missed. At present, there is postponing of all elective surgeries barring emergency procedures. As a front-line worker, the trainee is supposed to prepare and post an emergency case for operation. It was a time when I used to enter the operating room with so much enthusiasm and zeal to learn and treat patients. These surgeries, with which I used to assist with passion three months ago, have become stressful now. The operating room which once used to be a place of learning is now entirely a silent and stressful zone. Thinking back, I remember assisting high-risk seropositive cases with apprehension but not to this extent. But despite all this I am bound to treat and take care of patients, whatever the conditions or diseases might be, as I had taken the Hippocratic Oath on the start of this journey.

Academics during the COVID-19 times: Due to the strict imposition of the rules of social distancing by the administration, which is the key to break the chain of transmission of this highly infectious virus, there is a withholding of regular classroom academic seminars and classes. Also, the bedside teaching in clinical grand rounds is temporarily suspended to avoid crowding near the patients. It comes with the drawback that medical students in their clinical years will suffer from a lack of clinical experience impacting the skills they require to make on-point clinical decisions, which is of utmost importance. ${ }^{4}$ More amount of e-learning is promoted presently with online seminars and webinars on managing COVID-19 and other non-COVID-19 diseases, which is overall a new experience during this critical time. Few students find it very comfortable to take online theory classes at home, still, at the cost of missing the clinical courses. ${ }^{5}$ There is a risk of depression among students and having online courses is not always very pleasant due to frequent voice disturbances with connection problems and online examinations.

Mental health among medical students: We, medical students, are used to group study sessions and hangouts. Due to strictly abiding social distancing, the present situation has increased isolation of medical students and had a significant impact on mental health. In general, medical students are more prone to psychological distress and mental illness, leading to suicidal ideation.?

Strategy to overcome the COVID-19 crises: All elective surgical procedures are on hold, and the semi-elective cases are deferred if possible, by conservative treatment or radiological interventions. By this, a lot of resources, including indoor beds and PPE, are preserved, can be redirected for use by health care workers dealing directly with the COVID-19 patients. Also training all health care workers, irrespective of specialties, in critical care management for future preparedness, updating ourselves regarding recent happenings of the disease and helping in the active screening of all suspected patients is

MBBS, DCH. Surgical Resident, All India Institute of Medical Sciences (AIIMS), Bhubaneswar, India

2 MBBS, MS, FNB (MAS), FALS (Metabolic Surgery), FAIS. Additional Professor of Surgery, AIIMS, Bhubaneswar, India.

About the Author: Madhuri is pursuing her academic surgical training in the second year of a three years degree program. She has completed her two years of training in child health after her graduation.

Correspondence:

Prakash Kumar Sasmal

Address: Sijua, Patrapada, Bhubaneswar, Odisha 751019, India

Email: surg_prakash@aiimsbhubaneswar.edu.in

Editor: Francisco Javier Bonilla-Escobar Student Editors: Nikoleta Tellios Submission: Apr 30, 2020 Revisions required: May 5, 2020 Received in revised form: May 11, 2020 Acceptance: May 11, 2020 Publication: May 11, 2020 Process: Reviewed by Student Editors 


\section{Experience}

going to help fight against the dreadful disease until an effective medicine or vaccine is available.

\section{Lessons Learnt}

I just thought where we stand despite all the advancement in technology, improved health care and better diagnostic facilities possible today. Globally, a virus has disrupted the entire health system, economy and has taken a significant toll of precious human life. Seeing the present scenario, every nation and medical university needs to adequately increase the infrastructure to tackle similar situations and also train their future generation of health care providers more broadly to be able to manage critically ill patients during epidemics. It is high time - the global community should unite to fight against this invisible enemy of humanity strategically, or else it will cause colossal devastation, more so than the world war. 


\section{References}

1. World Health Organization, WHO. Coronavirus disease outbreak situation. Available from: https://www.who.int/emergencies/diseases/novel-coronavirus2019. WHO; Geneva, 2020. Accessed on 7th May 2020.

2. Government of India. India Fights Corona COVID-19. Available from: https://www.mygov.in/COVID-19. Accessed 7th May 2020.

3. Austin Alchon, Suzanne (2003). A pest in the land: new world epidemics in a global perspective. University of New Mexico Press. p. 21. ISBN 978-0-8263-2871 7. Archived from the original on 2019-04-01. Retrieved 2016-04-22.

4. Nguyen Tran Minh D, Pham Huy T, Nguyen Hoang D, Quach Thieu M. CoVID-19: Experience from Vietnam Medical Students. Int J Med Students. 2020 JanApr;8(1):62-63.
5. Pacheco Carrillo AM. The Utility of Online Resources in Times of COVID-19: A Mexican Medical Student Point of View. Int J Med Students. 2020 Jan-Apr;8(1):5859

6. Biavardi NG. Being an Italian Medical Student During the COVID-19 Outbreak. Int J Med Students. 2020 Jan-Apr;8(1):49-50.

7. Komer L. COVID-19 amongst the Pandemic of Medical Student Mental Health. Int | Med Students. 2020 Jan-Apr;8(1):56-57.

\section{Acknowledgments}

None.

Conflict of Interest Statement at Funding

The Authors have no funding, financial relationships or conflicts of interest to disclose.

Author Contributions

Writing - Original Draft: MC. Writing - Review at Editing: PKS.

Cite as:

Chaudary M, Sasmal PK. A Surgical Resident's Perspective about COVID-19 Pandemic: Unique Experience and Lessons Learnt. Int J Med Students. 2020 MayAug;8(2):156-8. 